\title{
Importance of Platelet Indices in Hepatocellular Carcinoma Prognosis
}

\author{
Erdim Sertoglu, $\mathrm{MD}^{1}$, Huseyin Kayadibi, $\mathrm{MD}^{2}$, and Metin Uyanik, $\mathrm{MD}^{3}$ \\ ${ }^{1}$ Biochemistry Laboratory, Ankara Mevki Military Hospital, Anittepe Dispensary, Ankara, Turkey; ${ }^{2}$ Biochemistry \\ Laboratory, Adana Military Hospital, Adana, Turkey; ${ }^{3}$ Department of Medical Biochemistry, Gulhane School of Medicine, \\ Ankara, Turkey
}

\section{TO THE EDITORS:}

We read with great interest the article by Shen et al. ${ }^{1}$ who aimed to evaluate the prognostic value of plateletbased indices, including platelet count, platelet/lymphocyte ratio (PLR), and aspartate aminotransferase (AST) to platelet ratio index (APRI) in hepatitis B virus (HBV)-induced hepatocellular carcinoma (HCC) after hepatic resection. In their conclusions, Shen et al. stated that elevated plateletbased inflammatory indices, especially APRI, were found to be associated with adverse characteristic features and poor prognosis in HCC, especially for patients with HBV infection or cirrhosis. However, we would like to share our thoughts and contributions to this study.

First, the APRI score is mostly calculated using Wai's formula: ${ }^{2} \quad$ APRI $=($ AST/upper limit of normal) $\times 100 /$ platelet count. As indicated in the formula, the upper limit of normal (ULN) of AST is one of the components of this formula and may vary among age/sex, gender, race/ethnicity, and laboratory specifications., ${ }^{3,4}$ According to Table 1 in the article by Shen et al., ${ }^{1}$ there were 292 male patients $(88 \%)$ and 40 female patients $(12.0 \%)$. It would be more appropriate to take into consideration this gender-dependent difference in ULN when calculating the APRI score. Moreover, the ULN value used in calculating the APRI score should be indicated in the Methods section of the original study.

Second, the authors indicated that they used $300 / \mathrm{mm}^{3}$ as the cut-off value for platelet count; however they did not

(C) Society of Surgical Oncology 2017

First Received: 29 October 2017;

Published Online: 9 November 2017

E. Sertoglu, MD

e-mail: erdimsertoglu@gmail.com refer to any literature for this cut-off value. Various platelet count cut-off values were determined and used in many other studies that were performed in similar patient groups. ${ }^{5}$ Receiver operating characteristic analysis should be performed to determine the most appropriate cut-off point for preoperative platelet count.

In conclusion, it is noted that routine assessment that included abdominal ultrasound and hematologic and biochemistry profiles are performed in the original study. Based on this information, other simple platelet-related indices such as spleen-platelet ratio index (SPRI) and ageSPRI (ASPRI) could be evaluated by using the current data provided in the original study.

DISCLOSURE Erdim Sertoglu, Huseyin Kayadibi, and Metin Uyanik state that there are no conflict of interests regarding the publication of this letter.

\section{REFERENCES}

1. Shen SL, Fu SJ, Chen B, Kuang M, Li SQ, Hua YP, et al. Preoperative aspartate aminotransferase to platelet ratio is an independent prognostic factor for hepatitis B-induced hepatocellular carcinoma after hepatic resection. Ann Surg Oncol. 2014;21(12):3802-9.

2. Wai CT, Greenson JK, Fontana RJ, Kalbfleisch JD, Marrero JA, Conjeevaram HS, et al. A simple noninvasive index can predict both significant fibrosis and cirrhosis in patients with chronic hepatitis C. Hepatology. 2003;38(2):518-26.

3. Sohn W, Jun DW, Kwak MJ, Park Q, Lee KN, Lee HL, et al. Upper limit of normal serum alanine and aspartate aminotransferase levels in Korea. J Gastroenterol Hepatol. 2013;28(3):522-9.

4. Mayo Clinic, Mayo Medical Laboratories. Tests and Procedures. Aspartate Aminotransferase (AST) (GOT). http:// www.mayomedicallaboratories.com/test-catalog/Clinical+ and+Interpretive/8360. Accessed 10 Jun 2014.

5. Maithel SK, Kneuertz PJ, Kooby DA, Scoggins CR, Weber SM, Martin RC, et al. Importance of low preoperative platelet count in selecting patients for resection of hepatocellular carcinoma: a multi-institutional analysis. J Am Coll Surg. 2011;212(4):638-48; discussion 648-50. 